\title{
1 Global Impacts of Climate Change on Avian Functional Diversity
}

2 Peter S. Stewart ${ }^{1,4 *}$, Alke Voskamp ${ }^{1,2}$, Matthias F. Biber ${ }^{2,3}$, Christian Hof ${ }^{2,3}$, Stephen G.

3 Willis $^{1}$, Joseph A. Tobias ${ }^{4}$

$4 \quad{ }^{1}$ Department of Biosciences, Durham University, DH1 3LE Durham, United Kingdom

$5 \quad{ }^{2}$ Senckenberg Biodiversity and Climate Research Centre (BiK-F), 60325 Frankfurt, Germany

$6 \quad{ }^{3}$ Terrestrial Ecology Research Group, Technical University of Munich, 85354 Freising,

7 Germany

$8 \quad{ }^{4}$ Department of Life Sciences, Imperial College London, Silwood Park, Buckhurst Road, 9 Ascot, SL5 7PY, UK.

10

*Corresponding author: peter.s.stewart@durham.ac.uk, +44(0)7503264088 (P. S. Stewart)

ORCID iDs: orcid.org/0000-0001-6338-6279 (P.S. Stewart), orcid.org/0000-0002-9528-

6317 (A. Voskamp), orcid.org/0000-0002-7726-988X (M.F. Biber), orcid.org/0000-00027763-1885 (C. Hof), orcid.org/0000-0002-8656-580 (S.G. Willis), orcid.org/0000-00032429-6179 (J.A. Tobias)

Keywords: climate change; functional diversity; functional traits; ecosystem function; rangeshift modelling; ecological forecasting

Type of paper: Primary Research Article

Running head: Climate change and avian functional diversity 


\section{Abstract}

24 Climate change is predicted to drive geographical range shifts in many taxa, leading to the formation of novel species assemblages and fluctuations in species richness worldwide. However, the effect of these changes on functional diversity is not yet fully understood, in part because comprehensive species-level trait data are generally lacking at global scales. Here we use morphometric and ecological trait data for 8269 terrestrial bird species to compare functional diversity (FD) of current and future bird assemblages under a medium emissions scenario. We show that future assemblages are likely to undergo substantial shifts in trait structure, with the direction and magnitude of these shifts varying with geographical location and trophic guild. Specifically, invertivore FD is projected to increase at higher latitudes with concurrent losses at mid-latitudes, reflecting poleward shifts in range, whereas frugivore FD is projected to fluctuate in many tropical regions with major declines in much of South America and New Guinea. We show that these projected changes in FD are generally greater than expected from changing species richness alone, indicating that projected FD changes are primarily driven by the loss or gain of functionally distinct species. Our findings suggest that climate change will drive continental-scale shifts in avian functional diversity, with potentially far-reaching implications for ecosystem functions and resilience. 


\section{Introduction}

Climate change is driving substantial shifts in species distributions worldwide (Walther et al., 2002; Parmesan \& Yohe, 2003). The magnitude and direction of these shifts vary across species, generating novel species assemblages which differ in structure and composition to those observed today (Williams \& Jackson, 2007), potentially resulting in changes to ecosystem functions, services and resilience (Barbet-Massin \& Jetz, 2015). Understanding and forecasting these changes to assemblage structure is an important step towards developing effective conservation strategies targeted at regions where ecosystem functions are likely to be compromised by climate change (Oliver \& Roy, 2015). However, few previous studies have gone beyond relatively simplistic estimates of changes in species distributions (Barbet-Massin \& Jetz, 2015; Gaüzère, Jiguet, \& Devictor, 2015), and thus the likely trophic structure and functioning of future assemblages under climate change remains unclear.

One method for estimating whether the functioning of future ecosystems is likely to be altered or impaired is to assess changes in the functional traits present in species assemblages (Barbet-Massin \& Jetz, 2015). Functional traits provide information about key dimensions of the ecological niche (Winemiller, Fitzgerald, Bower, \& Pianka, 2015; Pigot et al., 2016; Pigot et al., 2020), and functional diversity (FD) quantifies the range of functional traits present within a community (Petchey \& Gaston, 2002). Projected shifts in FD can therefore provide information about changes in the diversity and characteristics of niches occupied within species assemblages (Mouillot, Graham, Villéger, Mason, \& Bellwood, 2013; Pigot, Trisos, \& Tobias, 2016), and thus the likelihood of assemblages to sustain important ecological processes (Leitão et al., 2016; Petchey \& Gaston, 2002; Tilman, 2001; Villéger, Mason, \& Mouillot, 2008). Specifically, a reduction in trait diversity or a shift in trait structure suggests 
ecosystem functions will be lost or altered (Tilman et al., 1997; Cardinale, Palmer \& Collins, 2002; Díaz et al., 2013), potentially impacting ecosystem multifunctionality (Mouillot et al., 2011), and resilience (Bregman et al., 2016).

Assessing these functional impacts at macroecological scales has proved challenging because detailed trait data are generally available only patchily across large numbers of species. Most previous research has therefore focused at smaller spatial or taxonomic scales (e.g. Biswas, Vogt, \& Sharma, 2017; Van Zuiden et al., 2016; Mokany et al., 2015; Gaüzère, Jiguet, \& Devictor, 2015), making it difficult to know how far their results can be generalised. The only datasets available at a global scale that have previously been used to assess climate change impacts on assemblage trait structure are largely based on relatively crude species traits, such as diet categories or binary characters (e.g. diurnal versus nocturnal) (Barbet-Massin \& Jetz, 2015). The main drawback of these categorical traits is that vital information is lost during the process of categorisation, with many distinctly different species lumped within each particular category (Laureto, Cianciaruso, \& Samia, 2015; Weiher et al., 1999).

To address this issue, we compared the functional structure of current and future avian assemblages using a comprehensive dataset of morphological and ecological traits for 8269 terrestrial bird species worldwide (Pigot et al., 2020). For all species, we compiled eight continuous variables to capture variation in beak shape, wing shape, and the length of tarsus and tail. Together, these morphological traits provide and index of avian dispersal ability and trophic niche (Claramunt et al., 2012; Tobias et al., 2014; Pigot et al., 2020). In contrast, previous global studies have mainly been limited to a single continuous ecological trait body mass - which is a poor predictor of avian dispersal (Sheard et al. 2020) and only weakly informative about ecological niche differences (Pigot et al., 2020). We used this comprehensive trait dataset to calculate the functional diversity of future species assemblages estimated using recent species range projections (Hof et al., 2018) with a time horizon 
centred on 2050. Finally, we included additional analyses partitioning avian assemblages into two major dietary groups - frugivores and invertivores - which play important ecological roles through mutualistic interactions and insect predation, respectively (Pigot et al., 2016; Pigot et al., 2020; Şekercioğlu, 2006).

Specialist avian frugivores are vital seed dispersal agents, especially for large-fruited or large-seeded plants in tropical regions (Corlett, 2017; Snow, 1981). The loss of avian frugivores can substantially reduce recruitment of juvenile plants and limits the ability of plants to track climate change (Cordeiro \& Howe, 2003; McConkey et al., 2011; Mokany, Prasad, \& Westcott, 2014). Ultimately, declines in frugivore diversity may therefore impair carbon storage, potentially driving further climatic change (Bello et al., 2015). Avian invertivores in terrestrial ecosystems exert top-down control on invertebrate populations, including numerous phytophagous (herbivorous) insects and their larvae, thereby indirectly benefitting plant populations (Mäntylä, Klemola, \& Laaksonen, 2011) and boosting ecosystem productivity (Marquis \& Whelan, 1994). Invertivores also provide an important ecosystem service by limiting the impact of insect pests on agricultural crops (Jones, Sieving, \& Jacobson, 2005; Karp et al., 2013; Mols \& Visser, 2002).

The main aims of our study are to (1) re-evaluate the future impacts of climate change on the FD of avian assemblages, with particular focus on the structure of frugivore and invertivore communities, and (2) quantify the relative turnover of functionally redundant and functionally distinct species to determine whether changes in FD are primarily driven by the loss or gain of functionally distinct species. This second aim is related to the findings of Barbet-Massin and Jetz (2015), who highlighted the importance of functional turnover - the replacement of one subset of species by another set of species - in determining the impact of climate-driven range shifts on FD. They reported that projected shifts in FD were smaller than expected from observed changes in avian species richness, suggesting a tendency for 
turnover of functionally redundant species which contribute relatively little to the overall FD of the assemblage. We revisit this question in the context of continuous traits to examine the role of turnover in explaining projected shifts in FD for frugivorous and invertivorous birds.

Materials and Methods

\section{Current and Projected Avian Distributions}

We used baseline and projected distributions for 8269 terrestrial bird species worldwide from Hof et al. (2018) as binary presence-absence matrices, where each row represented a $0.5^{\circ} \mathrm{x}$ $0.5^{\circ}$ latitude-longitude grid cell (henceforth, "grid-cell assemblage"), and each column a bird species $(1=$ present, $0=$ absent $)$. The presence-absence data were derived by thresholding the projected probabilities of occurrence, using true skill statistics (TSS; Allouche, Tsoar \& Kadmon, 2006). As detailed in Hof et al., (2018), baseline distributions were derived from expert range maps produced by BirdLife International and NatureServe (2015), considering only areas where a species was extant or probably extant, was a native species and was resident or occurred regularly during the breeding season. Antarctica was excluded, leaving a total of 65546 grid-cell assemblages.

Species distribution models were used by Hof et al. (2018) to generate projected distributions for each bird species. These used current (1980-2009) data on temperature and precipitation from the meteorological forcing dataset EWEMBI (Lange, 2016) and future data from biascorrected global climate scenarios produced by ISIMIP phase $2 b$ (Frieler et al., 2017) for the year 2050 under the representative concentration pathway RCP6.0 (Fujino et al., 2006; Hijioka et al., 2008), incorporating four different global climate models (GCMs, GFDLESM2M, HadGEM2-ES, IPSL-CM5A-LR and MIROC5) which were chosen to reflect a representative spread of responses among the many GCMs available. We chose to use future 
projections for the period centred on 2050 because this period is most relevant for current climate change policy timelines and for conservation and ecosystem service mitigation planning. In addition, uncertainty in projections of biological change typically increase markedly for end-of-century projections (Baker et al. 2015). We selected RCP6.0 as a realistic medium-high climate-policy intervention scenario, which assumes a shift from coal towards oil, gas and renewables for energy (Masui et al. 2011). Two types of species distribution model (a general additive model, and a generalized boosted regression model) under each of the four global climate models were used to derive an ensemble projection. The models used pseudo-absences selected using a distance-weighted approach, in which absences beyond each species' baseline distribution were selected following a declining probability of $1 /\left(D_{e}\right)^{2}$ where $D_{e}$ is distance from the edge of the distribution (Hof et al., 2018). An intermediate dispersal scenario was used in which species could disperse to grid cells within $d / 2$ of their baseline range $(d=$ baseline range diameter $)$ and were constrained to neighbouring zoogeographic realms (Hof et al., 2018). We chose to use only a single dispersal scenario because while choice of dispersal range does affect the magnitude of species richness changes, particularly for species-poor assemblages, it has little influence on the broad-scale patterns observed (Hof et al., 2018). A blocking approach, as per Bagchi et al. (2013), was used to reduce the effect of spatial autocorrelation. For species with too few occurrences to perform blocking, models were instead on a random subset of $70 \%$ of the data and performance was evaluated using the left-out 30\%. Model validation was performed using the 'area under curve' (AUC) method to assess how models performed when used to predict current bird ranges (Hof et al., 2018). Species for which models performed poorly (AUC $<0.7$ across all models) were not included in the baseline or for future projections. Furthermore, only species which were terrestrial and which occupied 10 or more grid cells were included due to the difficulties associated with modelling species for which there are 
few presences (Hof et al., 2018). Therefore, of the 9882 bird species for which baseline data are available, 8269 species were considered in our analyses.

\section{Functional Traits}

For our species sample $(n=8269)$, we assembled morphological and ecological trait data from a comprehensive global dataset (Pigot et al., 2020). For each species, we compiled information on eight continuous traits (see Table S1) which provide information about key dimensions of the avian niche. Specifically, beak is linked to the trophic niche by indicating the size and type of food consumed (Lederer, 1975; Wheelwright, 1985; Hsu, Shaner, Chang, Ke, \& Kao, 2014; Pigot et al., 2020). Tarsus length, wing chord, first-secondary length and tail length are locomotory traits related to microhabitat utilisation, foraging strategy, and dispersal (Claramunt et al., 2012; Miles \& Ricklefs, 1984; Miles, Ricklefs, \& Travis, 1987; Sheard et al., 2020). Finally, body mass is related to various aspects of the avian niche including metabolic requirements (McGill et al., 2006), movement (Wotton \& Kelly, 2012), and foraging behaviour (Dial, Greene, \& Irschick, 2008). Beak length was taken from the tip to the anterior nares, as this metric has a lower measurement error than measuring from the base of the skull (Borras, Pascual, \& Senar, 2000). In combination, these traits provide an eight-dimensional quantitative morphological space — hereafter termed "morphospace" —in which the position of each species reflects key aspects of the trophic niche, including trophic level, diet and foraging behaviour (Pigot et al. 2020).

All trait values were log-transformed then z-transformed and converted into a distance matrix with the package Cluster (Maechler et al., 2018). We further adapted the matrix into a nested functional dendrogram using the "average" clustering algorithm in the ape package (Paradis and Schliep, 2018). Additionally, we combined the z-transformed traits in a principal component analysis (PCA). We only retained the first four principal component (PC) axes for 
further analysis because the computational requirements of functional diversity indices increase rapidly with increasing dimensionality and a four-dimensional morphospace is sufficient to describe variation in avian trophic niches (Pigot et al., 2020). Together, these axes accounted for $>95 \%$ of the variance in the functional trait data (see Table S2 for PC scores). All analyses were performed in R v3.5.1 (R Core Team, 2018).

Analysing functional trait structure of entire assemblages combines information across multiple different trophic levels and niches. While this provides a useful overview of general patterns, it can mask effects specific to particular ecological processes, unless these processes are partitioned into separate analyses (Bregman et al. 2014; Bregman et al. 2016; Cannon et al. 2019). To address this issue, we used published datasets (Tobias \& Pigot, 2019; Pigot et al., 2020) to subdivide our species sample into those classified as frugivores and terrestrial invertivores, which are associated with important ecosystem functions and services, namely seed dispersal and the top-down control of invertebrates, respectively (Şekercioğlu, 2006;

Karp et al., 2013; Bregman et al., 2016). Frugivores and terrestrial invertivores were defined as those terrestrial (i.e. non-aquatic) species for which $>50 \%$ of the diet consists of fruit or invertebrates, respectively.

\section{Analysis of Trait Structure}

We used current and future geographical ranges for 8269 bird species to calculate species richness occurring in all grid cells worldwide, producing a dataset of 65546 pairs of current and future assemblages. To quantify the trait structure of each grid-cell assemblage, we calculated four functional diversity metrics: Functional Diversity (FD; Petchey \& Gaston, 2002), Functional Richness (FRic; Villéger, Mason \& Mouillot, 2008), and Gaussian hypervolume (Blonder, 2017) volume (Hvol) and centroid coordinates (Hcent). 
$\mathrm{FD}$, the sum of branch lengths on a functional dendrogram, measures how species are dispersed in trait space (Petchey \& Gaston, 2002), with greater values of FD indicating a greater degree of trait complementarity. We calculated FD from the functional trait dendrogram for each assemblage, using the R package ape (Paradis and Schliep, 2018).

FRic, the volume of the smallest convex hull enclosing all trait values in an assemblage (Villéger et al., 2008), does not measure 'functional richness' per se because it is entirely dependent on the species with the most extreme trait values. However, it provides a useful indicator of the gain or loss of functionally extreme species. We calculated FRic based on the trait PC scores for each presence-absence-matrix row in all assemblages with five or more species using R package geometry (Habel et al., 2015).

The volume of a Gaussian hypervolume (Hvol) provides a different perspective to dendrogram-based approaches in that it focuses on the volume of morphospace occupied by species in an assemblage (Maire, Grenouillet, Brosse, \& Villéger, 2015; Blonder, 2017). A final method focuses on movement of the hypervolume centroid (Hcent), which can indicate important shifts in trait structure even in the absence of a change in functional diversity. Hvol and Hcent were calculated for each assemblage from the trait PC scores using the Silverman bandwidth estimate in the R package hypervolume (Blonder and Harris, 2018).

To measure how trait structure differed between current and future assemblages, the difference in FD, FRic and Hvol values between the baseline and projected distributions ( $\Delta \mathrm{FD}, \Delta \mathrm{FRic}$, and $\Delta \mathrm{Hvol}$ ) were calculated for each assemblage, as well as the Euclidean distance between the baseline and projected Hcent coordinates. Projected changes in species richness $(\Delta \mathrm{SR})$ were also calculated for each assemblage. Using the coordinates of each gridcell assemblage, we plotted maps of each metric $(\Delta \mathrm{FD}, \Delta \mathrm{FRic}, \Delta$ Hvol, Hcent Euclidean distance, and $\Delta \mathrm{SR}$ ) to examine the geographical distribution of our projected changes. 
To examine whether changes in FD were primarily driven by the gain or loss of functionally distinct species, observed $\Delta \mathrm{FD}$ was compared to expected $\Delta \mathrm{FD}$ values predicted from $\Delta \mathrm{SR}$. To reduce sensitivity to outliers, we used robust regression (Fox \& Weisberg, 2012), using the R package MASS (Venables and Ripley, 2002) with $\triangle F D$ as the response variable and

$240 \Delta \mathrm{SR}$ as the explanatory variable. The model output was used to predict $\Delta \mathrm{FD}$ from $\Delta \mathrm{SR}$, and the difference between observed and predicted $\triangle \mathrm{FD}$ was calculated (Residual FD). We then categorized each assemblage based on the percentage difference between observed and predicted $\Delta \mathrm{FD}$ (=residual/predicted). Assemblages in which FD was lost despite species richness (SR) gain (and vice versa) and where FD changed despite no SR change were given separate categories.

We conducted cladewide analyses at a global level for all 8269 species, and then repeated analyses separately for frugivores ( $n=898$ species) and invertivores $(n=4347$ species $)$.

\section{Results}

\section{a. Cladewide analyses}

In our geographical range forecasts, $1.1 \%$ of bird species $(n=89)$ had no suitable projected climate within their dispersal buffer and were thus considered to become extinct by 2050 . Shifts in the geographical distribution of the remaining $98.9 \%$ of bird species altered the diversity and structure of most grid-cell assemblages. The change in species richness between current (baseline) and future (projected) assemblages varied by geographic region (Figure 1a, Figure S1a), ranging from losses of 286 species to gains of 387 species $($ mean $=3.281$, $\mathrm{sd}=$ 31.3).

Our projections showed substantial changes in all functional diversity metrics, with the direction and magnitude of effects varying with geographical location (Figure 1b). Higher 

and Hvol losses occurred in New Guinea, the Caribbean, Eastern South America, and Eastern Mexico, continental Europe, and the southern Congo forest-savannah.

Gains in FD were generally greater than predicted from $\triangle \mathrm{SR}$ at higher latitudes, as well as western Australia and the Tibetan plateau (Figure 1e, dark blue regions), indicating that $\Delta \mathrm{FD}$ in these regions was primarily driven by the gain of functionally distinct species. FD losses were greater than predicted in much of Europe and western Asia, north Africa and the Middle East (Figure 1e, red regions), indicating losses of functionally distinct species. These losses were mostly over $50 \%$ greater than predicted from $\Delta \mathrm{SR}$ (Figure 1c,d). In contrast, FD losses which were lower than predicted, and thus driven by losses in functionally redundant species, were present in relatively few assemblages (Figure 1d), largely in Brazil, the southern Congo forest-savannah, the eastern USA, and parts of Indonesia (Figure 1e, yellow regions). However, observed $\triangle \mathrm{FD}$ in these regions was generally larger than in regions where $\Delta \mathrm{FD}$ was primarily driven by the loss of functionally distinct species (Figure 1c). Assemblages in which FD gains were smaller than predicted, and thus driven by the gain of functionally redundant species, were slightly less frequent than assemblages where FD gains were greater than predicted (Figure 1d) but were associated with larger observed FD increases, particularly in north-west South America (Figure 1c).

We found that FRic increased in few assemblages, mainly in parts of South America, western Australia, and northern areas of Russia and eastern Canada (Figure S2b). FRic losses were more widespread in eastern South America, the Caribbean, Venezuela, and New Guinea. 
handful of localised assemblages. Finally, the greatest Euclidean distances between baseline and projected Hcent occurred in the Sahara, the Arabian Peninsula, Northern Canada, and climate change effects on functional diversity, with uncertain implications for ecological processes.

\section{b. Frugivores}

292

To explore the implications of climate change for seed dispersal we assessed how species richness changed for a baseline dataset of 898 frugivorous species in 37924 grid-cell assemblages worldwide. We found that frugivore assemblages are most species-rich in the tropics, with a steep decline in diversity at higher latitudes, in both the current (baseline) and future (projected) scenarios (Figure S1b,c). According to projected frugivore distributions, $1972(5.2 \%)$ of these assemblages lose all frugivore species, and 17 species have no suitable projected climate within their dispersal buffer and are thus considered to be extinct by 2050 . frugivore species. Our projected future assemblages contain 881 frugivore species in 39016 grid-cell assemblages - a net gain of 1092 grid-cells ( $+2.9 \%$ relative to baseline). Changes in species richness ranged from losses of 54 species to gains of 72 species $($ mean $=0.03, \mathrm{sd}=$ $5.83)$.

Shifts in the trait structure of frugivore assemblages were not associated with latitude, as both gains and losses of FD occurred patchily across the tropics. The greatest frugivore FD and Hvol losses are projected to occur in New Guinea, Eastern South America, the Caribbean and 
In contrast, gains in FD and Hvol are projected to occur in the north-west of South America, as well as regions surrounding the Gulf of Mexico and patches of South-East Asia.

In most assemblages, $\Delta \mathrm{FD}$ was more extreme than predicted by $\Delta \mathrm{SR}$ (Figure 3b), indicating that changes in frugivore FD tended to be driven by the gain or loss of functionally distinct species. This result was more pronounced for frugivores compared with cladewide analyses. Gains in FD were greater than predicted from $\Delta \mathrm{SR}$ in southern and central Africa, south-east Asia, the central Andes and northern Australia (Figure 3c, dark blue regions). In most cases observed FD gains were over $50 \%$, and in some cases over $100 \%$, larger than predicted (Figure 3a,b). Losses in FD were greater than predicted from $\Delta \mathrm{SR}$ in eastern South America, eastern Australia, New Guinea, and patches of Sub-Saharan Africa and Arabia (Figure 3c, red regions). The majority of these losses were in excess of $50 \%$ greater than predicted from $\Delta \mathrm{SR}$ (Figure 3b). Furthermore, the observed FD losses in these regions were greater than those observed in any other regions (Figure 3a). We detected relatively few assemblages with lower FD losses than predicted by $\Delta \mathrm{SR}$. These were only associated with comparatively small changes in observed $\Delta \mathrm{FD}$ (Figure 3c, yellow regions). Regions which gained less FD than predicted by $\Delta \mathrm{SR}$ were also comparatively rare (Figure 3a,b), most notably occurring in the north-west of South America (Figure 3c, turquoise regions). Additionally, in many assemblages, especially beyond the tropics, no change in assemblage composition occurred (Figure 3c, light grey regions).

Widespread decreases in FRic occurred in South America and the Caribbean, as well as in Papua New Guinea and the eastern part of Indonesia (Figure 2c). FRic increases occurredd in north-west South America, west Africa, and Borneo . Analyses of FRic were constrained by low richness of frugivores outside the tropics: 22494 baseline assemblages and 22547 future assemblages contained fewer than five species, resulting in 23005 assemblages - most located in North America and Asia - for which $\Delta$ FRic could not be calculated. Finally, the 
Euclidean distance between current and projected Hcent was greatest in north-westernSouth America and in New Guinea, with other localised shifts in patches around the Gulf of Mexico and in north-eastern Australia (Figure 2d).

\section{c. Invertivores}

Terrestrial invertivores are extremely widespread in distribution, occurring in all 65546 baseline and future grid-cell assemblages. Geographical range projections revealed that 41 $(0.9 \%)$ of 4347 invertivore species in baseline assemblages had no grid-cells with suitable projected climate within their dispersal buffer and were thus assumed to become extinct by 2050. Many surviving invertivores shifted in distribution, driving changes in species richness ranging from losses of 145 species to gains of 194 species $($ mean $=1.63$, sd $=16.85$; Figure S1d, S1e). was far less patchy. Invertivore FD and Hvol underwent substantial and widespread increases across higher latitudes in the northern hemisphere, with losses at lower latitudes in the USA, Europe and Asia (Figure 4a, 4b). Outcomes in tropical regions were slightly less regular, with further large increases of FD and Hvol in north-west South America offset by losses in eastern South America, New Guinea, and the southern Congo forest-savannah.

Changes in invertivore FD were greater than predicted from $\triangle \mathrm{FD}$, especially for FD losses, and were thus primarily driven by the loss or gain of functionally distinct species (dark blue and red in Figure 5b). Echoing the pattern in raw FD, relative gains in invertivore FD were generally larger than predicted at higher latitudes in the northern hemisphere (Figure 5c, dark blue regions), whereas relative losses in invertivore FD were larger than expected at lower latitudes, including much of the central USA, Europe, and western Asia, as well as north 
Africa, India, and Australia (Figure 5c, red regions). In most of these regions, FD losses for many assemblages were over $50 \%$ greater than predicted by $\Delta \mathrm{SR}$. In scattered regions elsewhere, the relative losses of FD (Figure 5c, yellow regions), or relative gains in FD (Figure 5c, turquoise regions), were smaller than expected.

The same general pattern was observed using the FRic metric to quantify trait diversity in invertivore assemblages, with future assemblages gaining FRic mainly in patches at higher latitudes, whereas some largely tropical regions were characterised by losses in FRic (Figure 4c). The mean trait location for invertebrate assemblages was predicted to shift furthest in either arid or polar regions, with the Euclidean distance between current and projected Hcent peaking in the Sahara, the Arabian peninsula, northern Canada and Greenland (Figure 4d).

\section{Discussion}

Our analyses show that climate change is likely to drive substantial shifts in FD for terrestrial avian assemblages across all metrics examined, with the direction and magnitude of these shifts varying by geographical location and trophic niche. In particular, our results point to a future increase in FD of invertivores at higher latitudes with concurrent losses at midlatitudes, whereas projected shifts in FD for frugivores are more prominent in the tropics. In addition, we found that changes in FD were primarily driven by the loss or gain of functionally distinct species, particularly for frugivores. These findings suggest that the effects of climate change on future ecosystems vary across different trophic niches, and thus highlight the importance of focusing on specific ecological processes when exploring the impacts of environmental change.

When calculated for all birds, we found that shifts in trait FD occur relatively unevenly, with no clear latitudinal or geographical pattern, in line with previous analyses at the level of 
whole assemblages (Barbet-Massin \& Jetz, 2015). Overall, we found that species richness and metrics of functional diversity tended to increase slightly at higher latitudes, presumably as a result of species ranges tracking climatic niches towards the poles (Sorte \& Thompson, 2007; McQuillan \& Rice, 2015). The main limitations of focusing on such generalised effects are, first, that they can mask important changes occurring within different functional groups and, second, that they cannot be interpreted in the context of specific ecological functions (Bregman et al., 2016). When we focused analyses separately on frugivores and invertivores, we found contrasting patterns of climate change impacts on these two trophic groups.

For specialist frugivores, our projections showed a mosaic of different directional effects across the tropics. Across much of South America, New Guinea, and the southern Congo forest-savannah our projections displayed a dramatic decline in frugivore FD. As specialist avian frugivores are vital dispersal agents, especially for large-fruited or large-seeded plants in South America and Australasia (Corlett, 2017; Snow, 1981), these declines in FD could threaten seed dispersal in these regions, potentially damaging biodiversity by reducing the recruitment of juvenile plants and limiting the ability of plants to track climate change (Cordeiro \& Howe, 2003; McConkey et al., 2011; Mokany, Prasad, \& Westcott, 2014). These declines in frugivore diversity also threaten to impair carbon storage in tropical forest ecosystems, potentially driving further climatic change (Bello et al., 2015). However, the scarcity of data on how fruiting plants will respond to climate change hinders our ability to predict exactly how ecosystem functions will be affected (Corlett, 2011).

In contrast to the tropics, many mid and high-latitude frugivore assemblages were projected to remain identical in structure under climate change. However, these regions typically contain only one or two specialist frugivore species, perhaps because dispersal by birds is predominant in the tropics (Clark, Silman, Kern, Macklin, \& Islambers, 1999) with other 
modes of dispersal dominating at mid-to-high latitudes. Consequently, this result is probably of little importance for the provision of mid-to-high latitude seed dispersal.

Our projections for invertivores, on the other hand, show a much more distinct pattern of poleward shifts of species, particularly in the northern hemisphere. At mid-latitudes the loss of invertivores is likely to impact upon the top-down control of invertebrates, which in turn will affect other important ecosystem processes. For instance, forest productivity is likely to decline due to increased leaf damage from leaf-eating insects which are usually controlled by avian invertivores (Marquis \& Whelan, 1994). Additionally, the productivity of arable farms and orchards is expected to decline due to the release of invertebrate pests from top-down control by birds (Jones, Sieving, \& Jacobson, 2005; Karp et al., 2013; Mols \& Visser, 2002).

Meanwhile, the ecological effects of gains in invertivore FD at higher latitudes depend largely on how invertebrate populations respond to climate change. If northward shifts are a general trend across invertebrates, the demand for top-down control resulting from shifting invertivore diversity may be matched by the supply of control from invertivorous birds, and indeed long-term studies have observed northward shifts in European odonata (Hickling, Roy, Hill, \& Thomas, 2005) and lepidoptera (Parmesan et al., 1999) in response to warming over the past decades. However, other studies suggest that climate-driven changes in arthropod diversity are highly taxon and habitat-specific (Koltz, Schmidt, \& Høye, 2018). For instance, Muscid flies, one of the most abundant and diverse groups of Arctic invertebrates, declined in abundance by $80 \%$ between 1996 and 2014 within Greenland (Buddle \& Schmidt, 2018). Furthermore, invertebrate declines may be exacerbated by a reduction in flowering season arising from phenological differences between plant species in different areas (Høye, Post, Schmidt, Trøjelsgaard, \& Forchhammer, 2013). Together, these results suggest that rather than simple changes in abundance, we should expect complex changes in invertebrate community structure to occur (Callaghan et al., 2004), suggesting that some regions will 
experience trophic mismatches in which the supply of top-down control from invertivores differs greatly from invertebrate abundance, potentially impairing ecosystem functions (Durant, Hjermann, Ottersen, \& Stenseth, 2007; Schweiger, Settele, Schweiger, O., Settele, J., Kudrna, Klotz, \& Kühn, 2008).

The results of our cladewide projections are very similar to, and almost certainly driven by, the projections for invertivores. This is unsurprising, as invertivores constitute over half of our species sample. The trends in frugivore FD, and potentially trends for other functional groups, merely dampen the observed effects at a general level. Consequently, the implications of climate change for ecological functions are best determined by studying the effects at the level of each functional group.

Some trends were, however, consistently observed across all groups. For instance, both frugivore and invertivore projections displayed a major increase in functional diversity in north-western South America, centred approximately on the Colombia-Brazil border. This increase was less than expected from the increase in species richness, indicating that the trend is primarily driven by the addition of functionally redundant species with relatively similar traits. This raises the question of whether so many functionally similar species will be able to coexist within this novel assemblage. Coexistence between species is facilitated by divergence in functional traits and increasing phylogenetic distance (Barnagaud et al., 2014; Pigot, Jetz, Sheard, \& Tobias, 2018; Pigot \& Tobias, 2013), so coexistence between functionally similar, closely-related species may be impossible - a "forbidden combination" which must result in the local extinction of one species (Diamond, 1975). Even where competition does not lead to local extinction it may impact species' abundance (Fitt \&

452 Lancaster, 2017), rendering them vulnerable to extinction via stochastic causes (Lande, 1993). These impacts can further alter the functional structure of the assemblage (Mouillot et al., 2013), affecting ecosystem functions and resilience. Consequently, understanding how 
species interactions may structure novel assemblages under climate change is a key avenue for future research (Araújo \& Luoto, 2007; Lavergne et al., 2010; Pigot \& Tobias, 2013; Schleuning et al., 2016, 2020).

In our projections, changes in FD were usually greater than predicted from changes in species richness, indicating that changes in trait structure were primarily driven by the loss or gain of functionally distinct species. This contrasts with the findings of Barbet-Massin and Jetz (2015), who observed that far more assemblages, particularly in Africa and Asia, were driven by the loss of functionally redundant species. This discrepancy is likely due to differences between the trait data available: our fine-resolution continuous morphological traits enabled us to better detect functional differences between species than the relatively coarse categorical data used by Barbet-Massin and Jetz (2015).

The presence of functionally distinct species in an assemblage is vital for maintaining a breadth of ecosystem functions and services (Leitao et al., 2016), increasing the speed of ecological processes (Hedde, Bureau, Chauvat, \& Deca, 2010), and promoting ecosystem stability (O'Gorman et al., 2011). As such, the loss of these species has serious effects on the ecosystem, including the unpredictable loss of function (O'Gorman et al., 2011), and so we expect that regions in which more FD was lost than predicted from species richness are likely to undergo the greatest immediate negative impacts.

In principle, the loss of functionally redundant species is less likely to have such immediate impacts, because functionally similar species still remain to maintain ecosystem functions. However, the loss of functionally redundant species still has negative effects. Functional redundancy increases ecosystem resilience (Ehrlich \& Walker, 1998); loss of redundancy leaves brittle ecosystems, vulnerable to future perturbation. Our projections show that regions such as southern Africa and eastern South America, where less functional diversity was lost 
than predicted from species richness, may become vulnerable in this way. However, it is important to note that rapid impacts arising from the loss of functionally redundant species can still occur. There is no guarantee that one species will be able to compensate for the loss of another, for instance when one species is not abundant enough to compensate for the loss of a functionally similar species (Rosenfeld, 2002). Furthermore, other threats to avian diversity - including habitat loss, land-use change, and overhunting - may drive extinctions which leave seemingly redundant species as the sole bearers of vital ecosystem functions.

Our results differ from previous studies in that we estimate changes in FD based on more sophisticated informative continuous traits. This is an advance compared to the previously available method of calculating Gower dissimilarity between broad niche categories (e.g. Barbet-Massim \& Jetz, 2015), but it relies on the availability of suitable functional trait data. It is only very recently that comprehensive functional trait datasets have become available at a global scale (e.g. Pigot et al., 2020), and these data provide excellent opportunities for furthering our understanding of the likely impacts of climate change. A particularly important avenue for future research is the consideration of species interactions (Schleuning et al., 2020). This can be accomplished by combining functional trait and phylogenetic data, as functionally similar and closely-related species are less likely to coexist (Pigot et al., 2018). Additionally, trait-based approaches may allow us to place trends in avian assemblages within the context of changes in other taxa, such as invertebrates and fruit-bearing plants, to better understand how specific ecosystem functions are likely to be affected. Currently there are considerable gaps in our understanding of how novel species combinations (e.g. functional trait data may provide insights by determining how species are likely to interact.

502 For instance, as the dimensions of the beak are related to the size and type of food consumed 503 (Lederer, 1975; Wheelwright, 1985), these data can be combined with data on the resource's 
traits (e.g. fruit size and shape) to predict likely interactions. Such an approach has been effective in predicting frugivore-fruit interactions in Australian rainforests, especially for specialist frugivores (Moran \& Catterall, 2010), and predicting the functional roles of Neotropical birds in frugivore-fruit interactions (Dehling, Jordano, Schaefer, Bohning-Gaese, \& Schleuning, 2016). Advancing this line of research will allow us to predict the nature of functional changes within assemblages in far greater detail than is currently possible.

A couple of caveats must be borne in mind when interpreting our findings. Firstly, our projections are based solely on climatic data, and do not incorporate information on land-use change or other factors which may potentially drive functional diversity shifts. Our projections are also relatively coarse (grid cells represent areas over $3000 \mathrm{~km}^{2}$ at the equator). As species may be confined to microhabitats within each grid cell, and the climatic data represent an average over each grid cell, mismatches may occur between our projections and reality. Additionally, we used ensemble projections based on multiple models, and these models disagree to an extent about the exact responses of specific species and within specific grid cells. Furthermore, for these reasons, where our projections show no suitable range for species in the future, this should not be taken to mean that these species will certainly become extinct. Overall, while we believe our approach is robust for projecting broad macroecological trends under climate change, our findings should not be used to infer changes for specific grid-cell assemblages or individual species.

In conclusion, avian functional diversity is projected to undergo substantial, continental-scale shifts under climate change, with the direction and magnitude of trends varying with geographical location. In contrast to previous research, our analyses project that these shifts will be primarily driven by the loss or gain of functionally distinct species from assemblages. To further our understanding of how and where climate change is likely to impact ecosystem functions and resilience, future research should aim to incorporate species interactions and 
529 place changes in avian assemblages in the context of changes in other taxa, such as plants and

530 insects. With the advent of high-quality, global-scale functional trait data, we now have a

531 powerful tool with which to tackle these topics.

\section{Acknowledgements}

533 We would like to thank Daniel Swindlehurst for assistance with the code used to calculate the 534 functional diversity metrics. We would also like to thank Katerina Michalicckova, Bob 535 Cregan, and Santiago Lacalle Puig for providing HPC training and technical support. CH and 536 AV were supported by the German Federal Ministry for Education and Research (FKZ 537 01LS1617A), $\mathrm{CH}$ and MFB also acknowledges support from the Bavarian Ministry of

538 Science and the Arts via the Bavarian Climate Research Network (bayklif) and CH also from 539 the German Research Foundation (HO 3952/3-1). 
A)

5

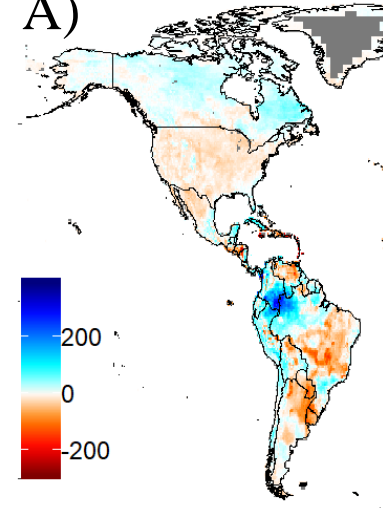

C)

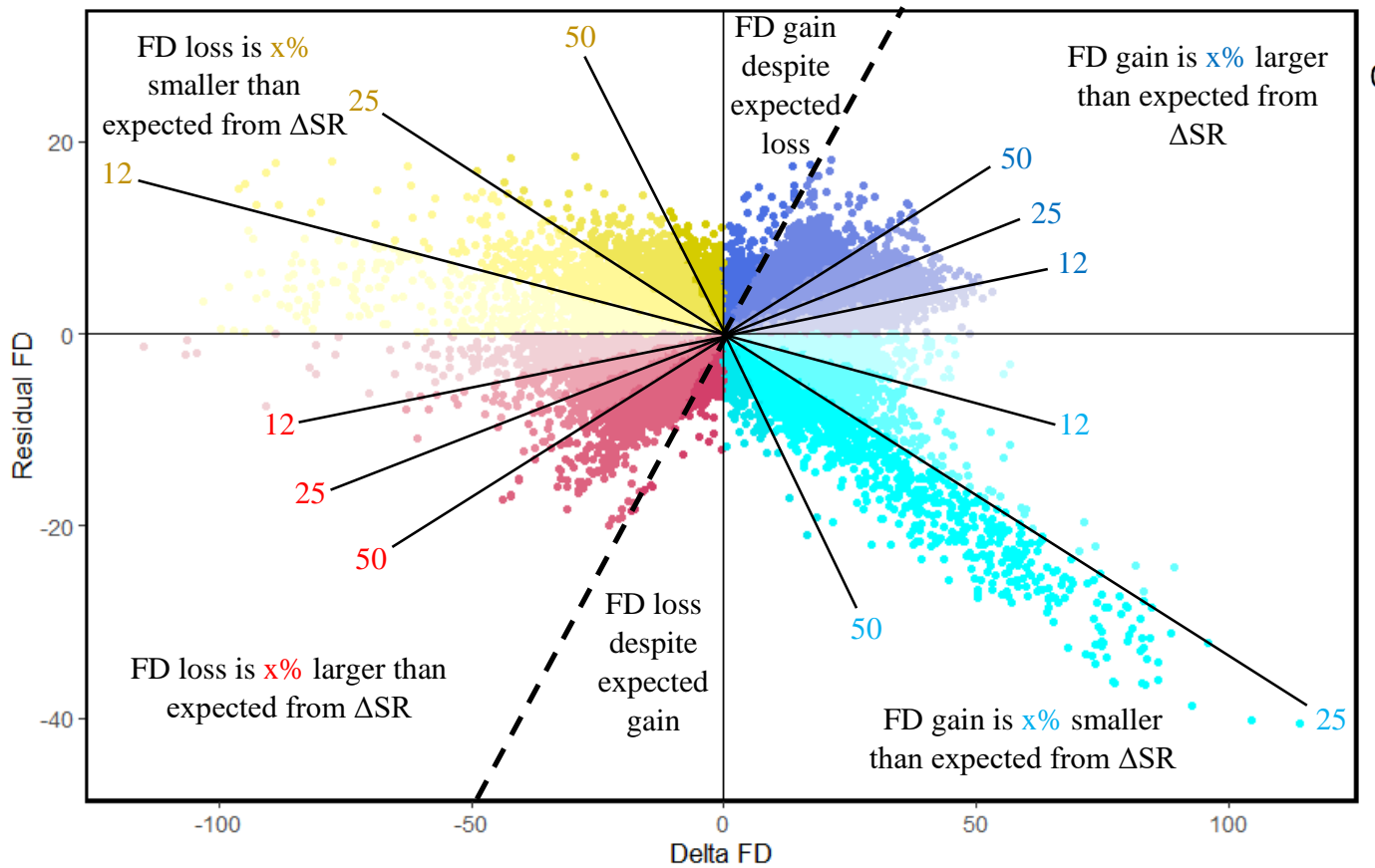

B)
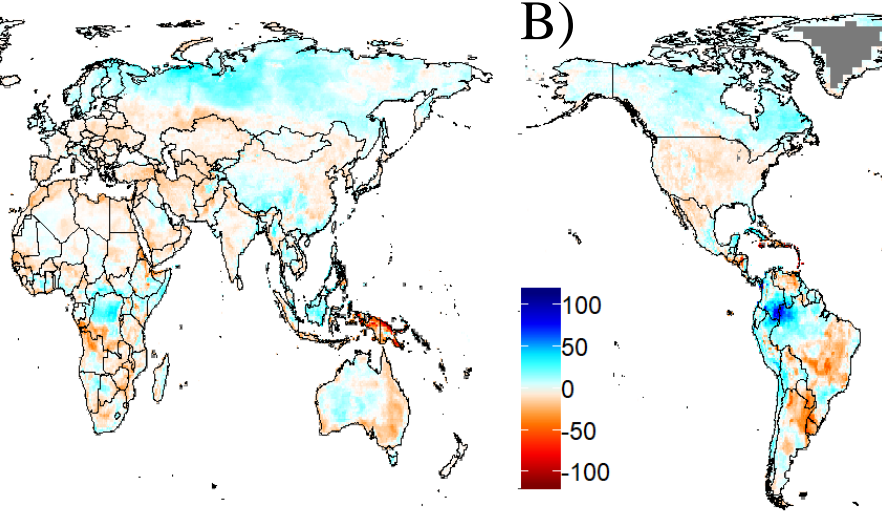

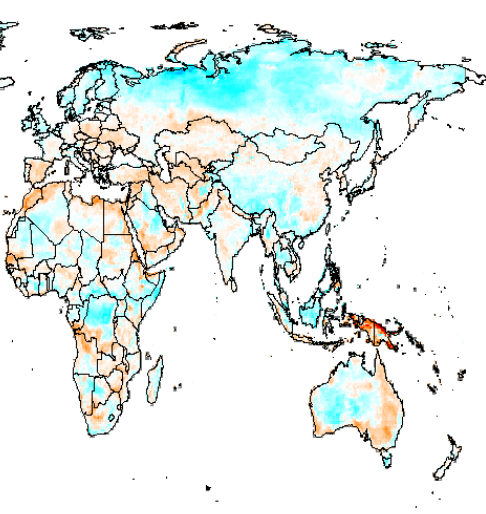

D)

Number of Assemblages

$0 \quad 2000 \quad 4000 \quad 6000 \quad 8000$

\section{\begin{tabular}{l}
\hline \\
\hline \\
\hline \\
\hline \\
\hline
\end{tabular}}

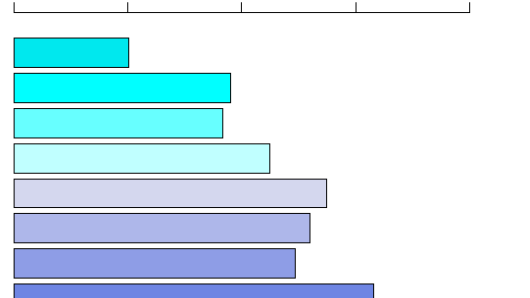

E)

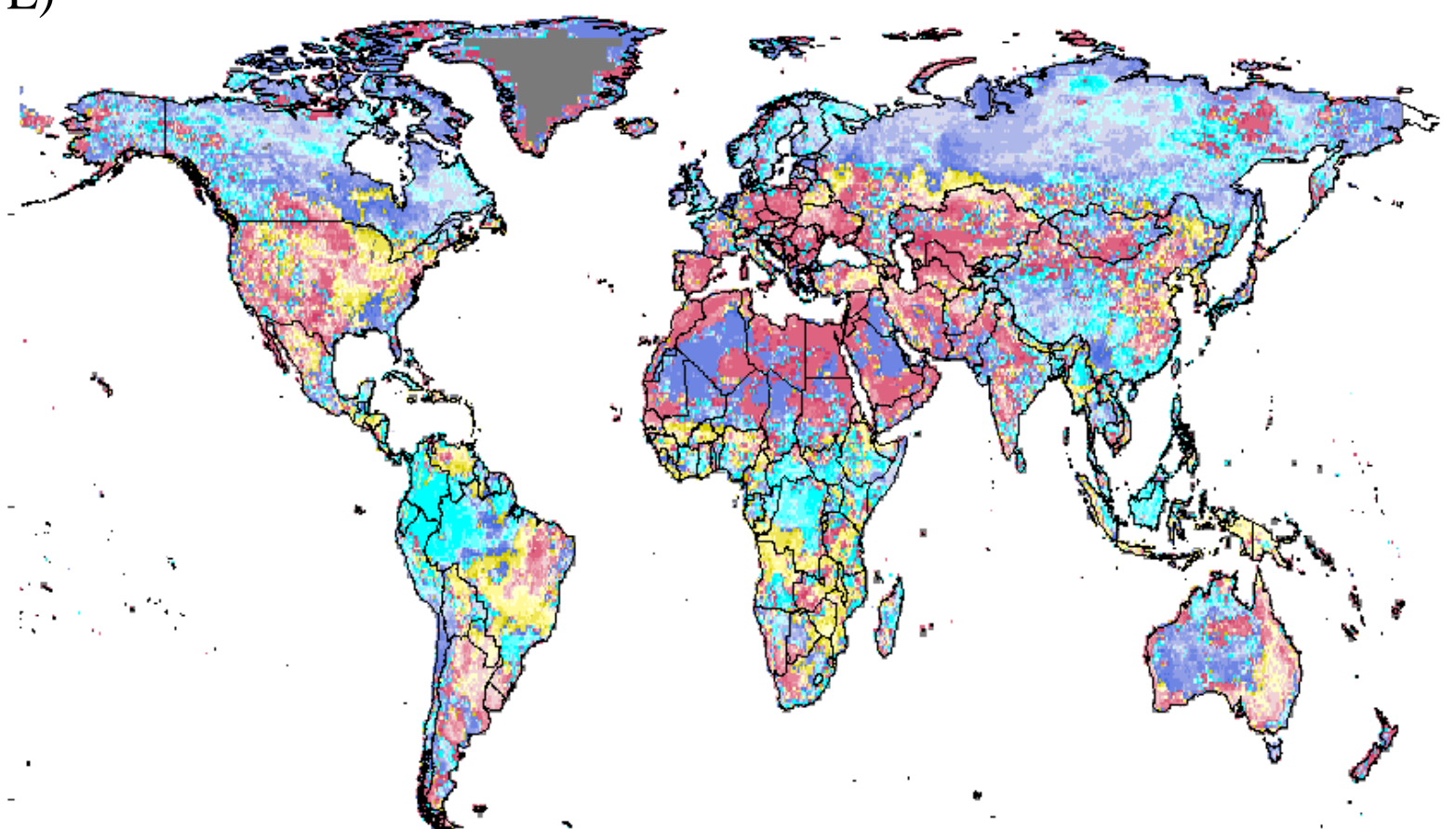


541 Figure 1. Projected cladewide changes in avian species richness (SR) and functional diversity (FD)

542 from 1995 to 2050 under the RCP6.0 emissions scenario, under an intermediate dispersal scenario. A)

543 Absolute change in SR; B) Absolute change in FD; C) The relationship between observed $\triangle F D$ and

544 Residual FD (the difference between observed $\triangle \mathrm{FD}$ and $\Delta \mathrm{FD}$ predicted from $\Delta \mathrm{SR}$ ). Annotations

545 denote regions where $\Delta \mathrm{FD}$ is larger or smaller than predicted from $\Delta \mathrm{SR}$, indicating assemblages

546 where $\Delta \mathrm{FD}$ is driven by the gain or loss of functionally distinct and functionally redundant species

547 respectively. Dashed line separates assemblages where $\Delta$ SR predicts FD loss (left) and FD gain

548 (right); D) The number of assemblages belonging to each scenario presented in C; E) Geographical

549 distribution of the scenarios presented in C. Dark grey areas in all maps indicate regions for which no

550 data were available 
A)

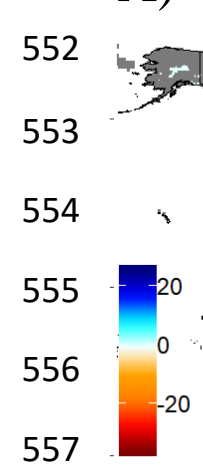

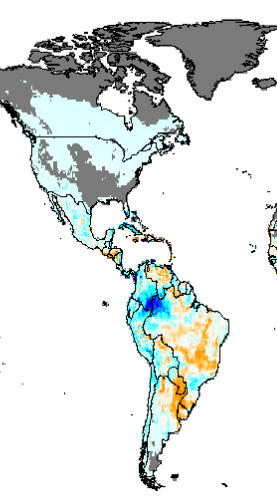

558 C)

559

560

561

562

563

564

565

566

567

568

569

570

571 which no data were available.

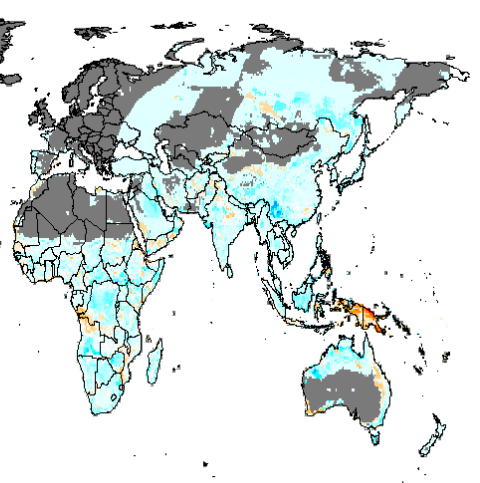

B)
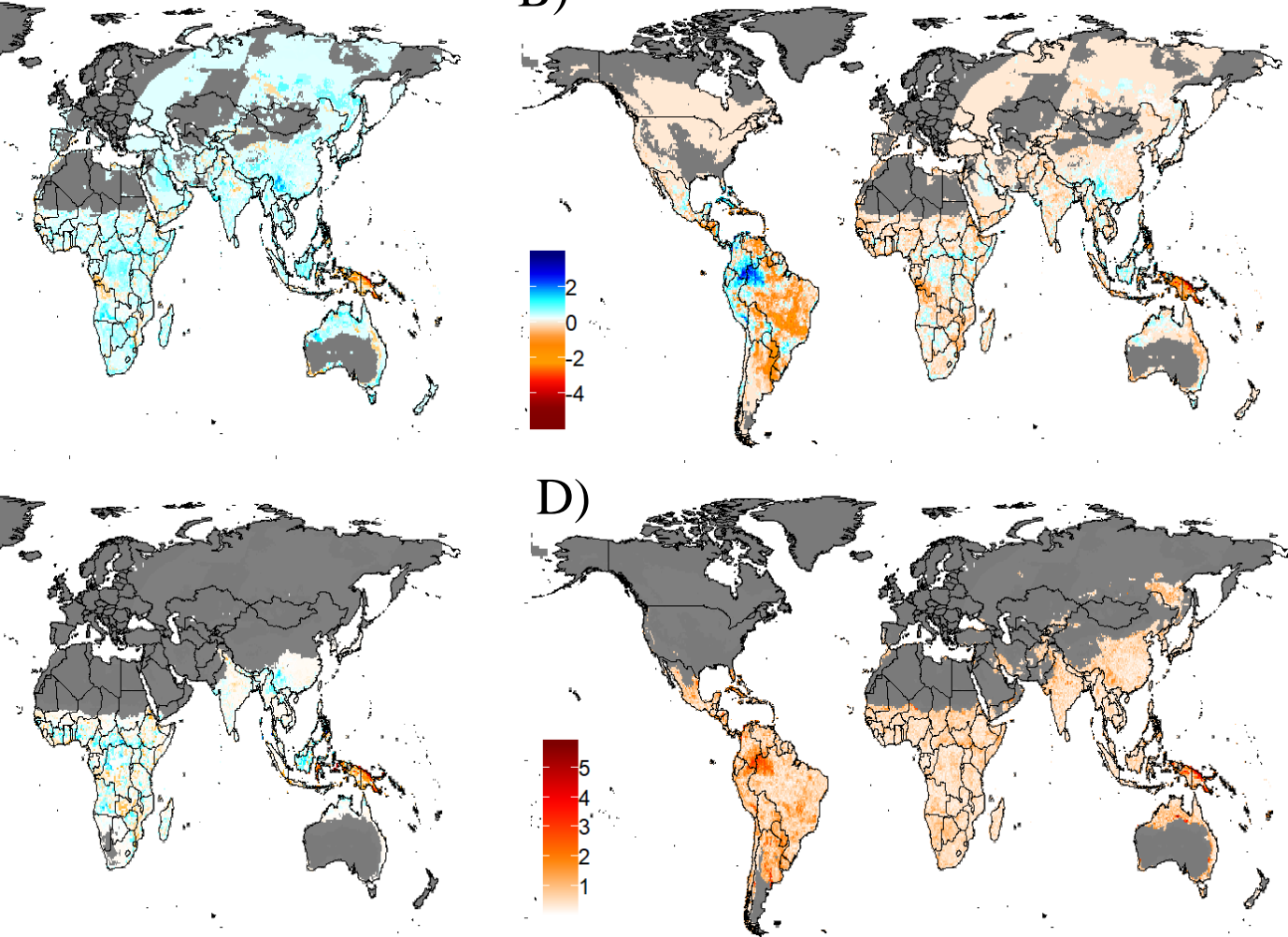

D)

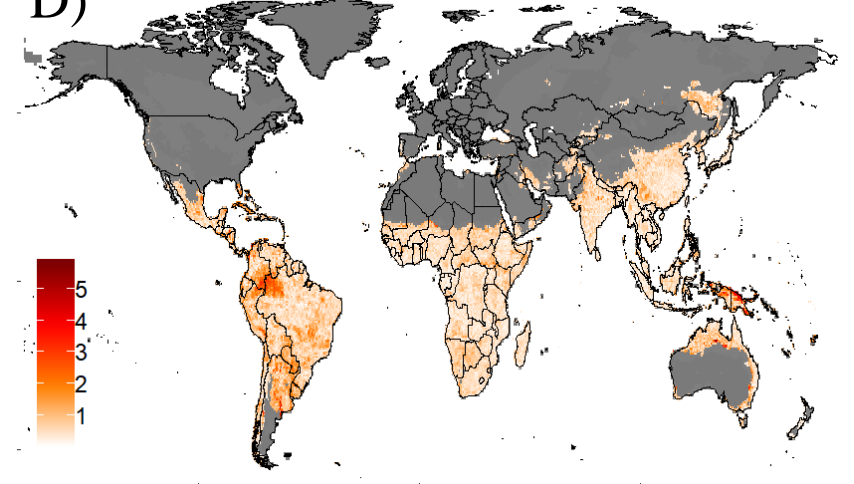

Figure 2. Projected changes in avian specialist frugivore functional diversity from 1995 to 2050 under the RCP6.0 emissions scenario, under an intermediate dispersal scenario. A) Functional diversity (FD); B) Hypervolume volume (Hvol); C) Functional richness (FRic); and D) Euclidean distance between current and predicted hypervolume centroids. Dark grey areas indicate assemblages for 
$\left.{ }^{572} \mathrm{~A}\right)$

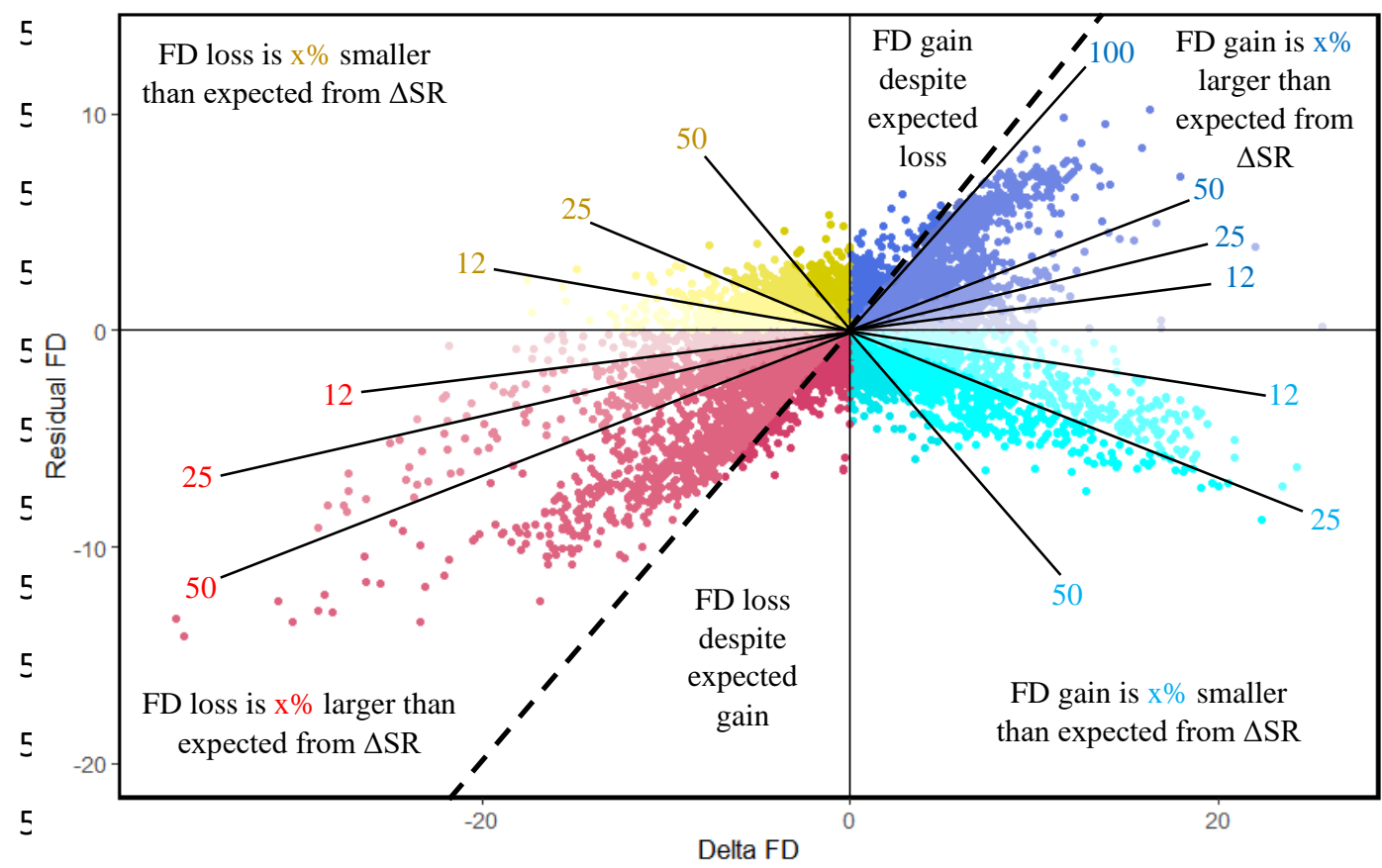

B)

Number of Assemblages J $5000 \quad 10000 \quad 15000$

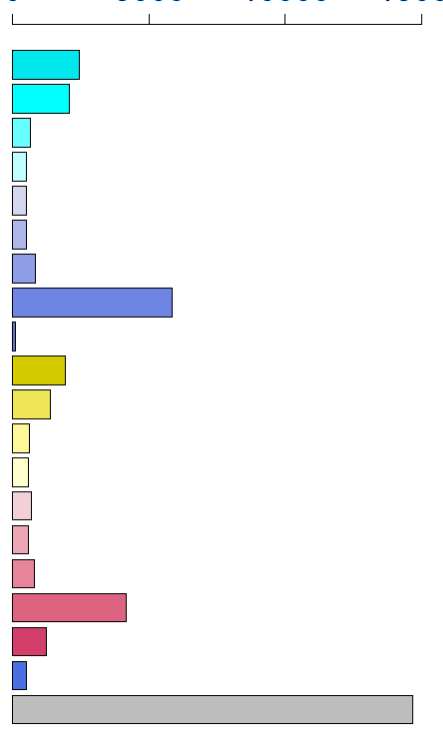

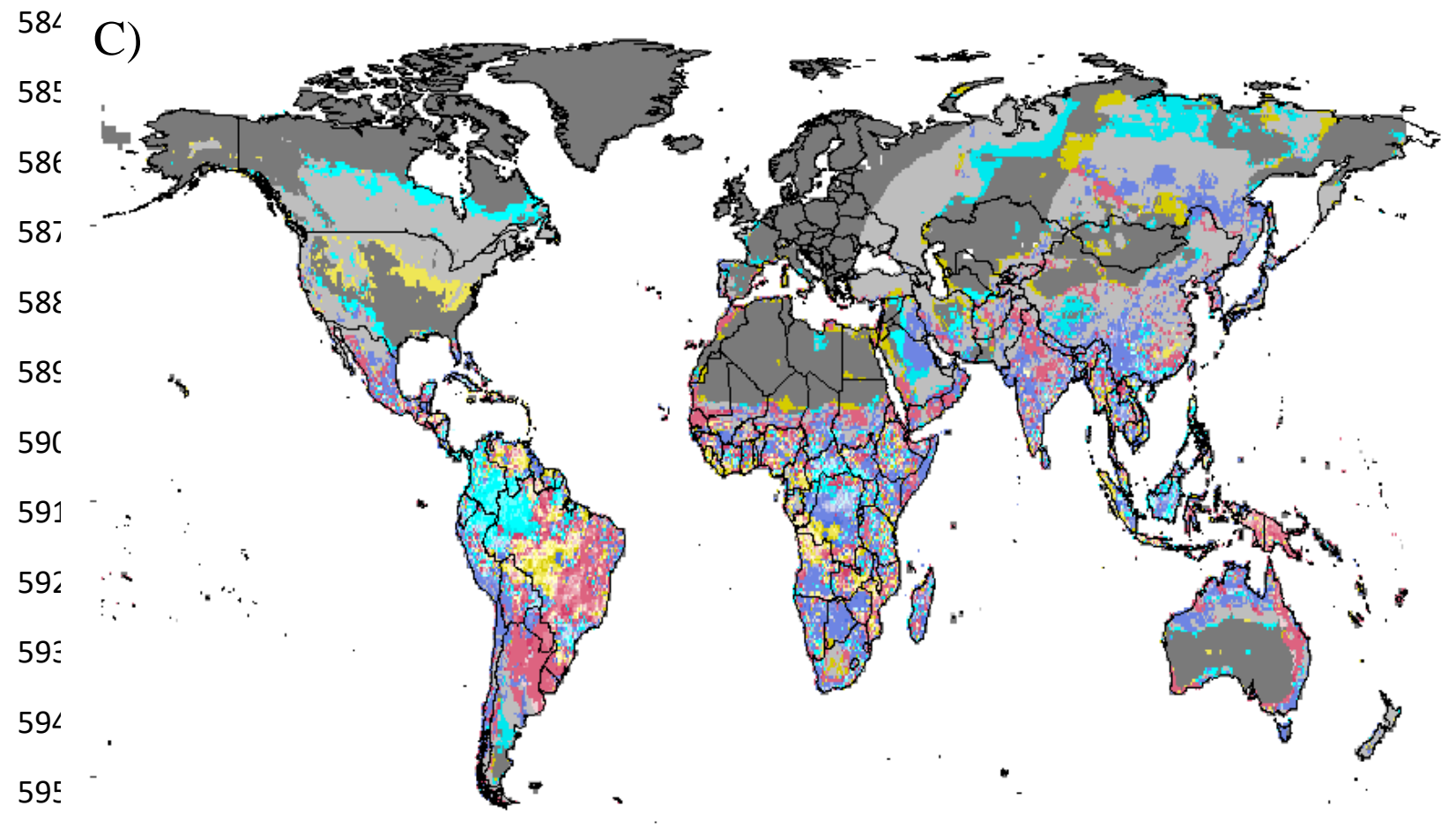

$59 \epsilon$

597 Figure 3. The relationship between $\Delta \mathrm{SR}$ and $\Delta \mathrm{FD}$ for specialist frugivores. A) The relationship

598 between observed $\Delta \mathrm{FD}$ and Residual FD (the difference between observed $\Delta \mathrm{FD}$ and $\Delta \mathrm{FD}$ predicted

599 from $\Delta \mathrm{SR}$ ). Annotations denote regions where $\Delta \mathrm{FD}$ is larger or smaller than predicted from $\Delta \mathrm{SR}$,

600 indicating assemblages where $\Delta \mathrm{FD}$ is driven by the gain or loss of functionally distinct and

601 functionally redundant species respectively. Dashed line separates assemblages where $\Delta \mathrm{SR}$ predicts

602 FD loss (left) and FD gain (right). B) The number of assemblages belonging to each scenario 
bioRxiv preprint doi: https://doi.org/10.1101/2020.06.01.127779; this version posted June 2, 2020. The copyright holder for this preprint (which was not certified by peer review) is the author/funder. All rights reserved. No reuse allowed without permission.

603 presented in A. C) Geographical distribution of the scenarios presented in A. Light grey areas indicate 604 regions in which no change in assemblage composition was observed. Dark grey areas indicate

605 regions for which no data were available.

606 
607

608

609

610

611

612

613

614 C)

615

616

617

618

619

620

621

622

623

624

625

626

627
A)
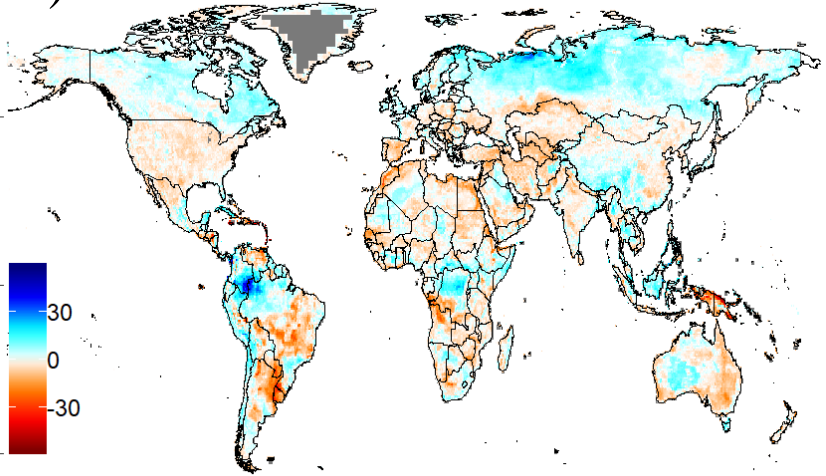

C)
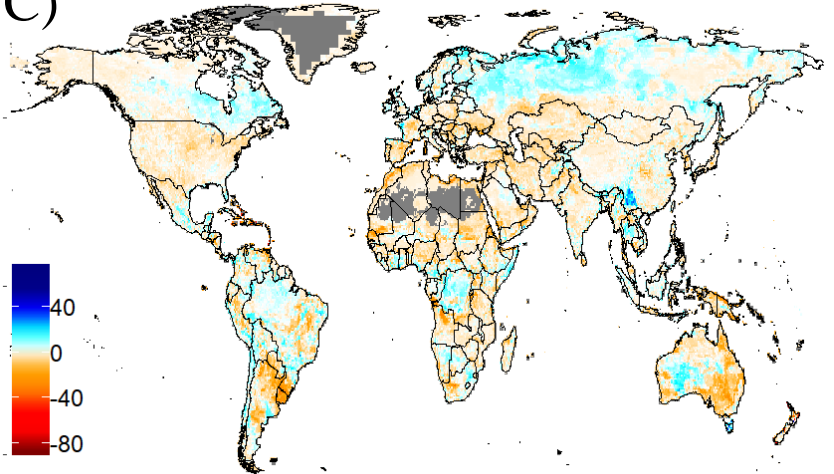

B)

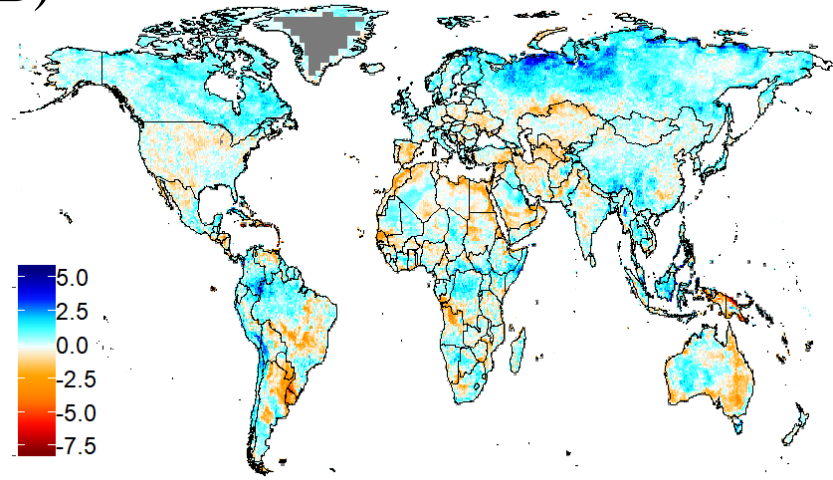

D)

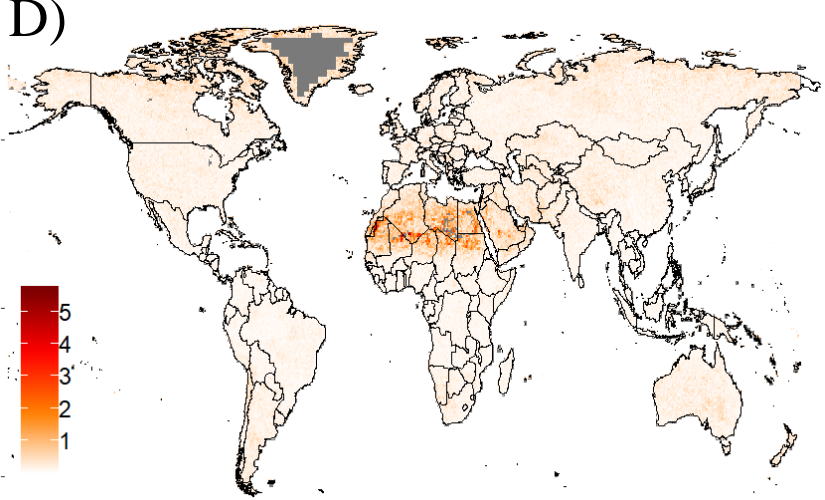

Figure 4. Projected changes in avian specialist invertivore functional diversity from 1995 to 2050 under the RCP6.0 emissions scenario, under an intermediate dispersal scenario. A) Functional diversity (FD); B) Hypervolume volume (Hvol); C) Functional richness (FRic); and D) Euclidean distance between current and predicted hypervolume centroids. Dark grey areas indicate assemblages for which no data were available. 
62

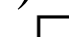
FD loss is $x \%$ smaller
than expected from $\Delta \mathrm{SR}$

63

63

63

63 논

63

63

63

63
63
63

63
63
63

33

63

640 C)

641

642

643

644

645

646

647

648

649

650

651

652

653

Figure 5. The relationship between $\Delta \mathrm{SR}$ and $\Delta \mathrm{FD}$ for specialist invertivores. A) The relationship

654

between observed $\Delta \mathrm{FD}$ and Residual FD (the difference between observed $\Delta \mathrm{FD}$ and $\Delta \mathrm{FD}$ predicted

655

from $\Delta \mathrm{SR}$ ). Annotations denote regions where $\Delta \mathrm{FD}$ is larger or smaller than predicted from $\Delta \mathrm{SR}$,

656

indicating assemblages where $\Delta \mathrm{FD}$ is driven by the gain or loss of functionally distinct and

657 functionally redundant species respectively. Dashed line separates assemblages where $\Delta$ SR predicts

658 FD loss (left) and FD gain (right). B) The number of assemblages belonging to each scenario 
bioRxiv preprint doi: https://doi.org/10.1101/2020.06.01.127779; this version posted June 2, 2020. The copyright holder for this preprint (which was not certified by peer review) is the author/funder. All rights reserved. No reuse allowed without permission.

659 presented in A. C) Geographical distribution of the scenarios presented in A. Light grey areas indicate 660 regions in which no change in assemblage composition was observed. Dark grey areas indicate 661 regions for which no data were available.

662 


\section{References}

664

665

666

667

668

669

670

671

672

673

674

675

676

677

678

679

680

681

682

683

684

685

686

687

688

689

690

691

692

693

694

695

696

697

698

699

700

701

Allouche O, Tsoar A, Kadmon R (2006) Assessing the accuracy of species distribution models: Prevalence, kappa and the true skill statistic (TSS). Journal of Applied Ecology. 43(6): 1223-1232.

Bagchi R, et al. (2013) Evaluating the effectiveness of conservation site networks under climate change: accounting for uncertainty. Global Change Biology. 19(4):1236-1248.

Baker, D. J., Hartley, A. J., Burgess, N. D., Butchart, S. H. M., Carr, J. A., Smith, R. J., Belle, E., Willis, S. G. (2015). Assessing climate change impacts for vertebrate fauna across the West African protected area network using regionally appropriate climate projections. Diversity and Distributions, 21, 991-1003.

Barbet-Massin, M., Jetz, W. (2015). The effect of range changes on the functional turnover, structure and diversity of bird assemblages under future climate scenarios. Global Change Biology, 21, 2917-2928.

Barnagaud, J. Y., Daniel Kissling, W., Sandel, B., Eiserhardt, W. L., Şekercioğlu, Ç. H., Enquist, B. J., Tsirogiannis, C., Svenning, J. C. (2014). Ecological traits influence the phylogenetic structure of bird species co-occurrences worldwide. Ecology Letters, 17, 811-820.

Bello, C., Galetti, M., Pizo, M. A., Magnago, L. F. S., Rocha, M. F., Lima, R. A. F., Peres, C. A., Ovaskainen, O., Jordano, P. (2015). Defaunation affects carbon storage in tropical forests. Science Advances, 1, e1501105.

Birdlife International and NatureServe - (2015) Bird species distribution maps of the world, Version 5.0 (Birdlife International, Cambridge, UK, NatureServe, Alrington, USA).

Biswas, S. R., Vogt, R. J., Sharma, S. (2017). Projected compositional shifts and loss of ecosystem services in freshwater fish communities under climate change scenarios. Hydrobiologia, 799, 135-149.

Blonder, B., Harris, D.J. (2018). Hypervolume: High Dimensional Geometry and Set Operations Using Kernel Density Estimation, Support Vector Machines, and Convex Hulls. R package version 2.0.11.

Blonder, B. (2017). Hypervolume concepts in niche- and trait-based ecology. Ecography, 41, 1441-1455.

Borras, A., Pascual, J., Senar, J. C. (2000). What do different bill measures measure and what is the best method to use in granivorous birds? Journal of Field Ornithology, 71, 606611.

Bregman, T.P., Lees, A.C., MacGregor, H.E.A., Darski, B., et al. (2016) Using avian functional traits to assess the impact of land-cover change on ecosystem processes linked to resilience in tropical forests. Proceedings of the Royal Society B. 283. 20161289

Buddle, C. M., Schmidt, N. M. (2018). Declining diversity and abundance of High Arctic fly assemblages over two decades of rapid climate warming. Ecography, 41, 265-277. 
Callaghan, T. V, Björn, L. O., Chernov, Y., Chapin, T., Christnsen, T. R., Huntley, B., Ims, R., Johansson, M., Jolly, D., Jonasson, S., Matveyeva, N., Panikov, N., Oechel, W., Shaver, G., Henttonen, H. (2004). Climate Change and UV-B Impacts on Arctic Tundra and Polar Desert Ecosystems: Effects on the Structure of Arctic Ecosystems in the Short- and Long-term Perspectives. Ambio: A Journal of the Human Environment, 33, 436-447.

Claramunt, S., Derryberry, E. P., Remsen, J. V., Brumfield, R. T. (2012). High dispersal ability inhibits speciation in a continental radiation of passerine birds. Proceedings of the Royal Society B, 279, 1567-1574.

Clark, J. S., Silman, M., Kern, R., Macklin, E., HilleRisLambers, J. (1999). Seed dispersal near and far: patterns across temperate and tropical forests. Ecology, 80, 1475-1494.

Cordeiro, N. J., Howe, H. F. (2003). Forest fragmentation severs mutualism between seed dispersers and an endemic African tree. PNAS, 100, 14052-14056.

Corlett, R. T. (2011). How to be a frugivore (in a changing world). Acta Oecologica, 37, 674-681.

Corlett, R. T. (2017). Frugivory and seed dispersal by vertebrates in tropical and subtropical Asia: An update. Global Ecology and Conservation, 11, 1-22.

Dehling, D. M., Jordano, P., Schaefer, H. M., Böhning-Gaese, K., Schleuning, M. (2016). Morphology predicts species' functional roles and their degree of specialization in plant - frugivore interactions. Proceedings of the Royal Society B, 283.

Dial, K. P., Greene, E., Irschick, D. J. (2008). Allometry of behavior. Trends in Ecology and Evolution, 23, 394-401.

Diamond, J. M. (1975). Assembly of Species Communities. In M. L. Cody J. M. Diamond (Eds.), Ecology and Evolution of Communities. Harvard: Harvard University Press. pp. 342-444

Durant, J. M., Hjermann, D. Ø., Ottersen, G., Stenseth, N. C. (2007). Climate and the match or mismatch between predator requirements and resource availability. Climate Research, 33, 271-283.

Egerer, M. H., Fricke, E. C., Rogers, H. S. (2018). Seed dispersal as an ecosystem service: frugivore loss leads to decline of a socially valued plant, Capsicum frutescens. Ecological Applications, 28, 655-667.

Ehrlich, P., Walker, B. (1998). Rivets and Redundancy. BioScience, 387.

Fitt, R. N. L., Lancaster, L. T. (2017). Range shifting species reduce phylogenetic diversity in high latitude communities via competition. Journal of Animal Ecology, 86, 543-555.

Fox, J., Weisberg, S. (2012). Robust regression in R. An R Companion to Applied Regression. SAGE Publications, Los Angeles. p. 1-16.

Frieler K, et al. (2017) Assessing the impacts of $1.5^{\circ} \mathrm{C}$ global warming - Simulation protocol of the Inter- Sectoral Impact Model Intercomparison Project (ISIMIP2b). Geoscientific Model Development. 10(12) p. 4321-4345. 
Fujino J, Nair R, Kainuma M, Masui T, Matsuoka Y (2006) Multigas mitigation analysis on stabilization scenarios using aim global model. The Energy Journal Special issue \#3, p. 343-354

Gaüzère, P., Jiguet, F., Devictor, V. (2015). Rapid adjustment of bird community compositions to local climatic variations and its functional consequences. Global Change Biology, 21, 3367-3378.

Habel, K., Grazman, R., Gramacy, R.B., Stahel, A., Sterratt, D.C. (2015). Geometry: Mesh Generation and Surface Tesselation. R. package version 0.3-6.

Hedde, M., Bureau, F., Chauvat, M., Decaëns, T. (2010). Patterns and mechanisms responsible for the relationship between the diversity of litter macro-invertebrates and leaf degradation. Basic and Applied Ecology, 11, 35-44.

Hickling, R., Roy, D. B., Hill, J. K., Thomas, C. D. (2005). A northward shift of range margins in British Odonata. Global Change Biology, 11, 502-506.

Hijioka Y, Matsuoka Y, Nishimoto H, Masui T, Kainuma M (2008) Global GHG emission scenarios under GHG concentration stabilization targets. Journal of Global Environment Engineering. 13. 97-108

Hof, C., Voskamp, A., Biber, M. F., Böhning-gaese, K., Engelhardt, E. K., Niamir, A., Willis, S. G., Hickler, T. (2018). Bioenergy cropland expansion may offset positive effects of climate change mitigation for global vertebrate diversity, PNAS. 1-6.

Høye, T. T., Culler, L. E. (2018). Tundra arthropods provide key insights into ecological responses to environmental change. Polar Biology, 41, 1523-1529.

Høye, T. T., Post, E., Schmidt, N. M., Trøjelsgaard, K., Forchhammer, M. C. (2013). Shorter flowering seasons and declining abundance of flower visitors in a warmer Arctic. Nature Climate Change, 3, 759-763.

Hsu, Y. C., Shaner, P. J., Chang, C. I., Ke, L., Kao, S. J. (2014). Trophic niche width increases with bill-size variation in a generalist passerine: A test of niche variation hypothesis. Journal of Animal Ecology, 83, 450-459.

Jones, G. A., Sieving, K. E., Jacobson, S. K. (2005). Avian Diversity and Functional Insectivory on North-Central Florida Farmlands. Conservation Biology, 19, 12341245.

Karp, D. S., Mendenhall, C. D., Sandi, R. F., Chaumont, N., Ehrlich, P. R., Hadly, E. A., Daily, G. C. (2013). Forest bolsters bird abundance, pest control and coffee yield. Ecology Letters, 15, 1339-1347.

Koltz, A. M., Schmidt, N. M., Høye, T. T. (2018). Differential arthropod responses to warming are altering the structure of Arctic communities. Royal Society Open Science, $5,1-17$.

Lande, R. (1993). Risks of Population Extinction from Demographic and Environmental Stochasticity and Random Catastrophes. The American Naturalist, 142, 911-927. 
Lange S (2016) EartH2Observe, WFDEI and ERA-Interim data Merged and Bias-corrected for ISIMIP (EWEMBI). doi:10.5880/PIK.2016.004.

Laureto, L. M. O., Cianciaruso, M. V., Samia, D. S. M. (2015). Functional diversity: An overview of its history and applicability. Natureza e Conservação, 13, 112-116.

Lederer, R. J. (1975). Bill Size, Food Size, and Jaw Forces of Insectivorous Birds. The Auk, 92, 385-387.

Lees, A. C., Newton, I., Balmford, A. (2013). Pheasants, buzzards, and trophic cascades. Conservation Letters, 6, 141-144.

Leitão, R. P., Zuanon, J., Villéger, S., Williams, S. E., Baratolo, C., Fortunel, C., Mendoça, F. P., Mouillot, D. (2016). Rare species contribute disproportionately to the functional structure of species assemblages. Proceedings of the Royal Society B, 283.

Maechler, M., Rousseeuw, P., Struyf, A., Hubert, M., Hornik, K. (2018). cluster: Cluster Analysis Basics and Extensions. R package version 2.0.7-1.

Maire, E., Grenouillet, G., Brosse, S., Villéger, S. (2015). How many dimensions are needed to accurately assess functional diversity? A pragmatic approach for assessing the quality of functional spaces. Global Ecology and Biogeography, 24, 728-740.

Mäntylä, E., Klemola, T., \& Laaksonen, T. (2011). Birds help plants: a meta-analysis of topdown trophic cascades caused by avian predators. Oecologia. 165, 143-151.

Marquis, R. J., Whelan, C. J. (1994). Insectivorous Birds Increase Growth of White Oak through Consumption of Leaf-Chewing Insects. Ecology, 75, 2007-2014.

Masui, T., Matsumoto, K., Hijioka, Y., Kinoshita, T., Nozawa, T., Ishiwatari, S., Kato, E., Shukla, P. R., Yamagata, Y., Kainuma, M. (2011). An emission pathway for stabilization at $6 \mathrm{Wm}^{-2}$ radiative forcing. Climatic Change, 109, 59-76.

McConkey, K. R., Prasad, S., Corlett, R. T., Campos-Arceiz, A., Brodia, J. F., Rogers, H., Santamaria, L. (2011). Seed dispersal in changing landscapes. Biological Conservation, 146.

McGill, B. J., Enquist, B. J., Weiher, E., Westoby, M. (2006). Rebuilding community ecology from functional traits. Trends in Ecology and Evolution, 21, 178-185.

McQuillan, M. A., Rice, A. M. (2015). Differential effects of climate and species interactions on range limits at a hybrid zone: Potential direct and indirect impacts of climate change. Ecology and Evolution, 5, 5120-5137.

Miles, D. B., Ricklefs, R. E. (1984). The correlation between ecology and morphology in deciduous forest passerine birds. Ecology, 65, 1629-1640.

Miles, D. B., Ricklefs, R. E., Travis, J. (1987). Concordance of Ecomorphological Relationships in Three Assemblages of Passerine Birds. The American Naturalist, 129, 347-364.

Mokany, K., Prasad, S., Westcott, D. A. (2014). Loss of frugivore seed dispersal services under climate change. Nature Communications, 5, 1-7. 
Mokany, K., Thomson, J. J., Lynch, A. J. J., Jordan, G. J., Ferrier, S. (2015). Linking changes in community composition and function under climate change. Ecological Applications, 25, 2132-2141.

Mols, C. M. M., Visser, M. E. (2002). Great tits can reduce caterpillar damage in apple orchards. Journal of Applied Ecology, 39, 888-899.

Moran, C., Catterall, C. P. (2010). Can Functional Traits Predict Ecological Interactions? A Case Study Using Rain forest Frugivores and Plants in Australia. Biotropica, 42, 318 326.

Mouillot, D., Graham, N. A. J., Villéger, S., Mason, N. W. H., Bellwood, D. R. (2013). A functional approach reveals community responses to disturbances. Trends in Ecology and Evolution, 28, 167-177.

O’Gorman, E. J., Yearsley, J. M., Tasman, P., Emmerson, M. C., Jacob, U., Petchey, O. L. (2011). Loss of functionally unique species may gradually undermine ecosystems. Proceedings of the Royal Society B, 278, 1886-1893.

Oliver, T. H., Roy, D. B. (2015). The pitfalls of ecological forecasting. Biological Journal of the Linnean Society, 115, 767-778.

Paradis E., Schliep K. 2018. ape 5.0: an environment for modern phylogenetics and evolutionary analyses in R. Bioinformatics.

Parmesan, C., Ryrholm, N., Stefanescu, C., Hill, J. K., Thomas, C. D., Descimon, H., Huntley, B., Kaila, L., Kullberg, J., Tammaru, T., Tennent, W. J., Thomas, J. A., Warren, M. (1999). Poleward shifts in geographical ranges of butterfly species associated with regional warming. Nature, 399, 579-583.

Parmesan, C., Yohe, G. (2003). A globally coherent footprint of climate change impacts across natural systems. Nature. 421, 37-42.

Petchey, O. L., Gaston, K. J. (2002). Functional diversity (FD), species richness and community composition. Ecology Letters, 5, 402-411.

Pigot, A., Bregman, T., Sheard, C., Daly, B., Etienne, R., Tobias, J.A. (2016) Quantifying species contributions to ecosystem processes: a global assessment of functional trait and phylogenetic metrics across avian seed-dispersal networks. Proceedings of the Royal Society B. 283: 20161597.

Pigot, A. L., Tobias, J. A. (2013). Species interactions constrain geographic range expansion over evolutionary time. Ecology Letters, 16, 330-338.

Pigot, A. L., Jetz, W., Sheard, C., Tobias, J. A. (2018). The macroecological dynamics of species coexistence in birds. Nature Ecology and Evolution, 2, 1112-1119.

Pigot, A.L., Sheard, C., Miller, E.T., Bregman, T., Freeman, B., Roll, U., Seddon, N., Trisos, C.H., Weeks, B., Tobias, J.A. (2020) Macroevolutionary convergence connects morphological form to ecological function in birds. Nature Ecology \& Evolution, 4 , 230-239. 
Pigot, A. L., Trisos, C. H., Tobias, J. A. (2016). Functional traits reveal the expansion and packing of ecological niche space underlying an elevational diversity gradient in passerine birds. Proceedings of the Royal Society B, 283, 1-9.

R Core Team (2018). R: A language and environment for statistical computing. R Foundation for Statistical Computing, Vienna, Austria. URL: https://www.R-project.org/.

Rosenfeld, J. S. (2002). Functional redundancy in ecology and conservation. Oikos, 98, 156162.

Schweiger, O., Settele, J., Kudrna, O., Klotz, S., Kühn, I. (2008). Climate change can cause spatial mismatch of trophically interacting species. Ecology, 89, 3472-3479.

Schleuning, M., Fründ, J., Schweiger, O., Welk, E., Albrecht, J., Albrecht, M., Beil, M., Benadi, G., Blüthgen, N., Bruelheide, H., Böhning-Gaese, K., Dehling, D.M., Dormann, C., Exeler, N., Farwig, N., Harpke, A., Hickler, T., Kratochwil, A., Kuhlmann, M., Kühn, I., Michez, D., Mudri-Stojnic, S., Plein, M., Rasmont, P., Schwabe, A., Settele, J., Vujic, A., Weiner, C.N., Wiemers, M., Hof, C. (2016). Ecological networks are more sensitive to plant than to animal extinction under climate change. Nature Communications, 7, 13965.

Schleuning, M., Neuschulz, E.L., Albrecht, J., Bender, I.M.A., Bowler, D.E., Dehling, D.M., Fritz, S.A., Hof, C., Mueller, T., Nowak, L., Sorensen, M.C., Böhning-Gaese, K., Kissling, W.D. (2020) Trait-based assessments of climate-change impacts on interacting species. Trends in Ecology \& Evolution, 35, 319-328.

Şekercioğlu, Ç. H. (2006). Increasing awareness of avian ecological function. Trends in Ecology \& Evolution, 21(8), 464-471.

Sheard, C., Neate-Clegg, M. H. C., Alioravainen, N., Jones, S. E. I., Vincent, C., MacGregor, H. E. A., Bregman, T. P., Claramunt, S., Tobias, J. A. (2020) Environmental and behavioural drivers of global gradients in dispersal inferred from avian wing morphology. Nature Communications, 11, 2463.

Snow, D. W. (1981). Tropical frugivorous birds and their food plants: a world survey. Biotropica, 13, 1-14.

Sorte, F. A. La, Thompson, F. R. (2007). Poleward shifts in winter ranges of North American birds. Ecology, 88, 1803-1812.

Tobias, J. A., Cornwallis, C. K., Derryberry, E. P., Claramunt, S., Brumfield, R. T., Seddon, N. (2014). Species coexistence and the dynamics of phenotypic evolution in adaptive radiation. Nature, 506, 359-363.

Tobias, J.A., Pigot, A.L. (2019) Integrating behaviour and ecology into global biodiversity conservation strategies. Philosophical Transactions of the Royal Society B. 374, 20190012.

Van Zuiden, T. M., Chen, M. M., Stefanoff, S., Lopez, L., Sharma, S. (2016). Projected impacts of climate change on three freshwater fishes and potential novel competitive interactions. Diversity and Distributions, 22, 603-614. 
Venables, W. N., Ripley, B. D. (2002) Modern Applied Statistics with S. Fourth Edition. Springer, New York.

Villéger, S., Mason, N. W. H., Mouillot, D. (2008). New Multidimensional Functional Diversity Indices for a Multifaceted Framework in Functional Ecology. Ecology, 89, 2290-2301.

Walther, G.-R., Post, E., Convey, P., Menzel, A., Parmesan, C., Beebee, T. J. C., Fromentin, J., Hoegh-Guldberg, O., Bairlein, F. (2002). Ecological responses to recent climate change. Nature, 416, 389-395.

Weiher, E., van der Werf, A., Thompson, K., Roderick, M., Garnier, E., Eriksson, O. (1999). Challenging Theophrastus: A common core list of plant traits for functional ecology. Journal of Vegetation Science, 10, 609-620.

Wheelwright, N. T. (1985). Fruit-Size, Gape Width, and the Diets of Fruit-Eating Birds. Ecology, 66, 808-818.

Williams, J. W., Jackson, S. T. (2007). Novel climates, no-analog communities, and ecological surprises. Frontiers in Ecology and the Environment, 5, 475-482.

Winemiller, K. O., Fitzgerald, D. B., Bower, L. M., Pianka, E. R. (2015). Functional traits, convergent evolution, and periodic tables of niches. Ecology Letters, 18, 737-751.

Wotton, D. M., Kelly, D. (2012). Do larger frugivores move seeds further? Body size, seed dispersal distance, and a case study of a large, sedentary pigeon. Journal of Biogeography, 39, 1973-1983. 